\title{
Glasgow Coma Scale on Presentation Predicts Outcome in Endovascular Treatment for Acute Posterior Large-Vessel Occlusion
}

\author{
(D) A.H. Chiu, (DD.A. Hince, and (D)W. McAuliffe
}

\begin{abstract}
SUMMARY: Use of mechanical thrombectomy for stroke has increased since the publication of trials describing outcome improvement when used in the anterior circulation. These results, however, cannot be directly translated to the posterior circulation. While a high NIHSS score has demonstrated an association with poor outcomes in posterior stroke, the NIHSS is weighted toward hemispheric disease, and complex scores potentially delay definitive imaging diagnosis. We performed a retrospective analysis to ascertain whether any rapidly obtainable demographic or clinical and imaging data have a correlation with patient outcome postthrombectomy. Seventy-three cases were audited between September 2010 and October 2017. Presenting with a Glasgow Coma Scale score of $>13$ meant that the odds of reaching the primary end point of functional independence (defined as a 90 -day modified Rankin Scale score of 0-2) were 5.70 times greater; similarly, presenting with a posterior circulation ASPECTS of $>9$ resulted in the odds of reaching the primary end point being 4.03 times greater. Older age correlated to a lower odds of independence $(0.97$, $p=.04)$.
\end{abstract}

ABBREVIATIONS: $\mathrm{F}-\mathrm{mTICI}=$ final modified TICI score; GCS = Glasgow Coma Scale; I-mTICI = initial modified TICI score; $\mathrm{MT}=$ mechanical thrombectomy; $\mathrm{mTICl}=$ modified $\mathrm{TICl}$ PC = posterior circulation; PLVO = posterior large-vessel occlusion; RACE = Rapid Arterial oCclusion Evaluation

$\mathrm{T}$ he caseload of mechanical thrombectomy (MT) for stroke has increased since the publication of trials ${ }^{1-6}$ describing the benefit in the anterior circulation. Given the questionable efficacy of IV-tPA in the treatment of posterior circulation stroke, endovascular treatment has long been considered an option for posterior large-vessel occlusion (PLVO). ${ }^{6-8}$ Trials pertaining to the anterior circulation, however, cannot be translated directly to PLVO. While a high NIHSS score has also been associated with poor outcomes in posterior stroke, ${ }^{9,10}$ this association has been questioned, ${ }^{11,12}$ given that the NIHSS is weighted toward hemispheric disease. ${ }^{13}$ Other scales ${ }^{14}$ have been suggested to increase the accuracy in posterior strokes; however, the use of these complex scores potentially delays the imaging diagnosis, which is unarguably more definitive for guiding management. We thus sought to identify whether any rapidly obtainable demographic

Received October 18, 2019; accepted after revision February 19, 2020.

From the Neurological Intervention and Imaging Service of Western Australia (A.H.C., W.M.), Western Australia Health, Sir Charles Gairdner, Royal Perth, and Fiona Stanley Hospitals, Perth, Australia; Medical School, Division of Medicine (A.H.C., W.M.), University of Western Australia, Perth, Australia; and Institute for Health Research (D.A.H.), University of Notre Dame, Fremantle, Australia.

Please address correspondence to Albert H. Chiu, MBBS (Hons.) FRANZCR CCINR, Neurological Intervention and Imaging Service of Western Australia, Sir Charles Gairdner Hospital, 1st Floor, G Block, Hospital Ave, Nedlands WA 6009, Australia; e-mail: albert.h.chiu@gmail.com

Indicates article with supplemental on-line table.

http://dx.doi.org/10.3174/ajnr.A6497

or clinical- and imaging-related data that are routinely collected for PLVO have a correlation with outcome.

\section{MATERIALS AND METHODS Background}

Our neurointerventional service has, for $>10$ years, been organized as a single multisite state department encompassing 3 tertiary/quaternary hospitals, providing all elective and acute neurovascular services. During data collection, stroke care underwent an evolution from a neurology-driven thrombolysis service (organized per hospital) to a state-wide MTdriven system. Ambulance triage using the Rapid Arterial oCclusion Evaluation score (RACE) ${ }^{15}$ was implemented in 2016. Ambulances would be diverted to 1 of 2 MT centers on the basis of the RACE, and on arrival to the emergency department, a "code stroke" was activated.

As the service grew, the decision to proceed to MT evolved. Use of the NIHSS became sporadic, given the nature of PLVO but also because of the availability of RACE and increasingly expeditious transfer to CT. The NIHSS was hence not included in the study. Imaging protocols were hospital-dependent but included noncontrast CT brain and CTA; use of perfusion varied. MR imaging was not performed routinely before intervention. Decision-making evolved to a parallel model with neurology and neurointervention teams attending every code stroke, with the 
decision for IV-tPA and/or MT made collaboratively. MT was performed with the patient under general anesthetic using stent retriever a or suction techniques, with use of balloon-guide catheters and/or distal-access catheters per operator preference.

\section{Data Collection}

This was a retrospective analysis of a prospectively collected audit data base encompassing all cases at all 3 hospitals. Adult patients treated between September 2010 and October 2017 with MT for an intracranial PLVO were included. Demographics collected include age, sex, and time of onset (or wake-up/unknown-onset). Clinical parameters collected included the Glasgow Coma Scale (GCS) score on presentation, and whether IV-tPA was administered. Imaging was reviewed, and the extent of infarction on pretreatment noncontrast brain CT was graded per the posterior circulation ASPECTS (PC-ASPECTS) score. ${ }^{16}$ The presence of posterior communicating arteries and the level of occlusion were assessed on CTA; if this assessment was not possible, information was sought on treatment angiography. Thrombectomy-related data included the initial modified TICI (I-mTICI) score, final modified TICI score (F-mTICI; both with modified TICI [mTICI] 3 defined by the entire basilar territory), and time of recanalization. Safety data recorded included procedural complications, separated into clinically relevant or technical (intracranial perforation/extravasation, nonterritory embolism, or vessel dissection), imaging complications on routine day 1 noncontrast brain CT (subarachnoid/intraparenchymal hemorrhage, subdivided into symptomatic/asymptomatic), and clinically relevant access complications (vascular occlusion, percutaneous thrombin treatment, transfusion, or surgical repair). The 3-month mRS score was determined at routine 3-month outpatient clinic. The primary end point was defined as functional independence, which was defined as a 3 -month $\mathrm{mRS}$ of $\leq 2$. The diagnosis for the cause of stroke (cardiogenic, intracranial/extracranial atheroma, dissection, paradoxical, iatrogenic, or otherwise) was recorded. Missing data were retrieved from medical records and the PACS.

\section{Statistical Analysis}

Descriptive data are presented using means/SDs, median/interquartile ranges, and frequency/percentage as appropriate. The relationship between $\mathrm{mRS}$ and predictors of interest (time to recanalization, GCS, IV-tPA, sex, age, and PC-ASPECTS) was considered using univariable and multivariable logistic regression models. The multivariable model was developed using backward elimination, and $P<.05$ was used to determine predictor inclusion in the model. The association between mRS and F-mTICI (dichotomized as $0-2 \mathrm{a}$ versus $2 \mathrm{~b}-3$ ) was assessed using the Fisher exact test because this variable perfectly predicts the mRS and therefore a logistic model cannot be fitted. Similarly, the relationship between mRS and I-mTICI was considered with the Fisher test because of the small sample size in the $2 \mathrm{~b}-3$ group. The sensitivity, specificity, and area under the curve for significant predictors of interest were determined using a cutoff value that produced the maximum product of sensitivity and specificity in predicting the primary end point. ${ }^{17}$ The probability cutoff from the final multivariable model was determined in the same way and was used to assess the prediction performance of this model. A bootstrap procedure (with 100 repetitions) was used to determine the $95 \%$ confidence interval for these cut-points. All analyses were conducted using STATA, Version 15.0 (StataCorp, College Station, Texas), and $P<.05$ was considered significant.

The study was reviewed and approved by the local institutional review board for audit processes (Governance Evidence Knowledge Outcomes [GEKO] System, Department of Health, Western Australia).

\section{RESULTS}

Seventy-nine cases were recorded; 6 patients were excluded due to incomplete follow-up data. Of the 73 remaining, 26 patients (35.62\%) were women. Ages ranged from 18 to 92 years (mean, $64.11 \pm 15.51$ years). The time of onset of stroke was unknown in 14 patients $(19.18 \%)$, and the median presentation GCS was 10 (interquartile range, 8). A breakdown of presentation PCASPECTS, posterior communicating artery status, and level of occlusion is given in Table 1. IV-tPA was administered in 11/73 patients (15.07\%). I-mTICI 0 was seen in 66/73 (90.41\%); F-mTICI $\geq 2$ b was achieved in $63(86.30 \%)$. Further breakdown is provided in Table 1. The median total time of ictus to recanalization was 6.5 hours (interquartile range, 8.2 hours).

The procedural complication rate was $4.11 \%$ (3.80\% when including 6 patients with missing 3-month data); this consisted of 2 cases of perforation, and 1 technical complication (dissection) that was non-flow-limiting and did not contribute to patient deterioration.

Postprocedurally, there were 2 cases of new symptomatic intraparenchymal hemorrhage (considered natural history), 1 symptomatic SAH ( 1 of the perforations), and 1 of access complication requiring both percutaneous thrombin injection and blood transfusion, for a delayed complication rate of 5.48\% $(5.06 \%$ when including 6 patients with missing 3-month data). Final outcomes are listed in the On-line Table.

At 3-month follow-up, 25 patients (34.25\%) reached the primary end point $(\mathrm{mRS} \leq 2)$. The most common cause for PLVO was cardiogenic with $26 / 73$ cases (35.62\%), followed by intracranial atheroma in 20 (27.40\%); details are provided in Table 2. Twenty-five patients (34.25\%) died.

GCS, PC-ASPECTS, and age were found to be significant predictors (Table 3). Presenting with a GCS of $>13$ meant that the odds of reaching the primary end point were 5.70 times greater; similarly, presenting with a PC-ASPECTS of $>9$ resulted in the odds of reaching the primary end point being 4.03 times greater. No cut-point could be found for age. These are also significant on the multivariable model; a predicted probability of 0.32 (95\% CI, $0.18-0.46)$ has a sensitivity of 0.83 (95\% CI, 0.61-0.95) and specificity of 0.71 ( $95 \% \mathrm{CI}, 0.55-0.84)$ for $\mathrm{mRS} \leq 2$. This produces an area under the receiver operating characteristic curve of 0.77 (95\% CI, 0.55-0.84). Details are listed in Table 4. No correlation was seen for IV-tPA, sex, or time from ictus to recanalization (Table 3). F-mTICI $\geq 2 \mathrm{~b}$ was significant for predicting $\mathrm{mRS} \leq 2$, whereas I-mTICI was not (Table 5). Given the difficulty in meaningfully categorizing the level of occlusion and the robustness of the posterior communicating arteries, the frequencies were found 
Table 1: Initial and final $\mathrm{mTICl}$ for the $\mathbf{7 3}$ patients with complete data

\begin{tabular}{|c|c|}
\hline Category & No. (\%) \\
\hline \multicolumn{2}{|l|}{ Level of occlusion } \\
\hline RVA, no LVA & 2 \\
\hline RVA, small LVA & 1 \\
\hline RVA, large LVA & 0 \\
\hline LVA, no RVA & 0 \\
\hline LVA, small RVA & 1 \\
\hline LVA, large RVA & 0 \\
\hline Bilateral VA & 1 \\
\hline Lower basilar trunk & 22 \\
\hline Upper basilar trunk & 9 \\
\hline Basilar apex & 29 \\
\hline RPCA & 2 \\
\hline LPCA & 5 \\
\hline Bilateral PCA & 1 \\
\hline \multicolumn{2}{|l|}{ PC-ASPECTS } \\
\hline 10 & 23 \\
\hline 9 & 8 \\
\hline 8 & 14 \\
\hline 7 & 10 \\
\hline 6 & 5 \\
\hline 5 & 2 \\
\hline 4 & 1 \\
\hline 3 & 1 \\
\hline 2 & 0 \\
\hline 1 & 0 \\
\hline 0 & 0 \\
\hline No data & 9 \\
\hline \multicolumn{2}{|l|}{ PcomA } \\
\hline None & 30 \\
\hline $1,<1 \mathrm{~mm}$ & 9 \\
\hline $1, \geq 1 \mathrm{~mm}$ & 4 \\
\hline 2 , both $<1 \mathrm{~mm}$ & 7 \\
\hline $2,1<1 \mathrm{~mm} ; 1 \geq 1 \mathrm{~mm}$ & 9 \\
\hline 2 , both $\geq 1 \mathrm{~mm}$ & 12 \\
\hline No data & 2 \\
\hline \multicolumn{2}{|l|}{ I-mTICI } \\
\hline 0 & $66(90.41)$ \\
\hline 1 & $5(6.85)$ \\
\hline $2 b$ & $1(1.37)$ \\
\hline $2 c$ & $1(1.37)$ \\
\hline \multicolumn{2}{|l|}{$\mathrm{F}-\mathrm{mTICl}$} \\
\hline 0 & $6(8.22)$ \\
\hline 1 & $3(4.11)$ \\
\hline $2 a$ & $1(1.37)$ \\
\hline $2 b$ & $20(27.40)$ \\
\hline $2 c$ & 7 (9.59) \\
\hline 3 & $36(49.32)$ \\
\hline \multicolumn{2}{|l|}{$\mathrm{F}-\mathrm{mTICl}$ ranges } \\
\hline $0-2 a$ & 10 (13.70) \\
\hline $2 b-3$ & $63(86.30)$ \\
\hline
\end{tabular}

Note:-PcomA indicates posterior communicating artery; RVA, right vertebral artery; LVA, left vertebral artery; VA, vertebral artery; RPCA, right posterior cerebral artery; LPCA, left posterior cerebral artery; PCA, posterior cerebral artery.

to be too small to model; however, a breakdown is provided in Table 1 .

For completeness, in the 6 patients who had incomplete follow-up data, 2 were women. All presented with an I-mTICI of 0. F-mTICI consisted of $0(n=1), 2 \mathrm{a}(n=2), 2 \mathrm{~b}(n=1)$, and 3 $(n=2)$. Causes of stroke were cardiogenic $(n=1)$, extracranial atheroma $(n=1)$, iatrogenic $(n=1)$, intracranial atheroma $(n=2)$, and unknown $(n=1)$.
Table 2: Final documented causes for posterior circulatory occlusion in the 73 patients with complete data

\begin{tabular}{lc}
\hline \multicolumn{1}{c}{ Cause } & No. (\%) \\
\hline Cardiogenic & $26(35.62)$ \\
Intracranial atheroma & $20(27.40)$ \\
Unknown & $9(12.33)$ \\
Dissection & $7(9.59)$ \\
Other NOS & $5(6.85)$ \\
latrogenic & $3(4.11)$ \\
Extracranial atheroma & $2(2.74)$ \\
Paradoxical & $1(1.37)$ \\
\hline
\end{tabular}

Note:-NOS indicates not otherwise specified.

\section{DISCUSSION}

With MT, our workflow surrounding patients with stroke has changed to prehospital activation, assessment by multiple specialties, and patient transfer from the ambulance to the emergency department, through imaging, and potentially to the neurointerventional suite. Because of the potential time lost, there is interest in how time may be saved. While complex clinical scores may give an edge to prognostication, even the well-studied NIHSS has not been demonstrated to perform better; Turc et al ${ }^{18}$ found, in 1004 patients, that cut-points of NIHSS $\geq 11$ and RACE $\geq 5$ both achieved accuracies of $79 \%$ for large-vessel occlusion, but with the NIHSS only demonstrating a $5 \%$ improvement in the false-negative rate $(27 \%$ versus $33 \%$, respectively) and an inferior false-positive rate ( $17 \%$ versus $15 \%$, respectively). Introducing more scores increases interoperator variability, especially when a mix of junior and senior clinicians is involved, as is the reality of acute stroke care. The additive value of these scores to actual patient care, in this time-sensitive environment, must hence be questioned.

Most studies suggest poorer outcomes for PLVO compared with anterior circulatory large-vessel occlusion, ${ }^{19,20}$ but these also generally demonstrate a longer ictus-to-recanalization time. Alawieh et al, ${ }^{21}$ however published an analysis of 536 patients in which there was no significant difference in onset-to-groin times between anterior and posterior circulation thrombectomies (or procedural times) and correlating equivalent functional outcomes. Although we did not find an association between ictus to recanalization and outcome, the above study continues to reinforce the need to minimize time lost.

Our results are notable in that favorable GCS and PCASPECTS scores predict significant odds of functional independence. GCS demonstrated a trend toward significance in an earlier article by Mourand et al, ${ }^{22}$ albeit with a smaller population of 31 patients. The GCS has been considered a biomarker for outcome previously; however, in these studies it was either used in a different timeframe, in patients treated without thrombolysis or thrombectomy, solely with thrombolysis, or with outdated devices such as the Merci Retriever System (Concentric Medical, Mountain View, CA), ${ }^{23-25}$ all of which have little relevance to modern thrombectomy. The relevance of established infarct at presentation to outcome is self-explanatory, but the cut-point of $>9$ suggests that any established infarction is clinically relevant. While a cut-point for age could not be established, for each year of increasing age, a 3\%-5\% 
Table 3: Univariable and multivariable odds ratios for the association between each predictor variable and binary mRS (where mRS $>2$ is the reference group)

\begin{tabular}{|c|c|c|c|c|c|c|c|}
\hline Predictor & No. & Univariable OR & $95 \% \mathrm{Cl}$ & $P$ & Multivariable $\mathrm{OR}^{\mathrm{a}}$ & $95 \% \mathrm{Cl}$ & $P$ \\
\hline Time to recanalization & 67 & 1.01 & $-0.99-1.03$ & .37 & & & \\
\hline GCS & 73 & 1.18 & $1.04-1.33$ & .01 & 1.21 & $1.04-1.42$ & .001 \\
\hline \multicolumn{8}{|l|}{ IV-tPA } \\
\hline No & 62 & 1.00 & & & & & \\
\hline Yes & 11 & 1.12 & $0.29-4.25$ & .87 & & & \\
\hline \multicolumn{8}{|l|}{ Sex } \\
\hline $\mathrm{F}$ & 26 & 1.00 & & & & & \\
\hline M & 47 & 1.28 & $0.46-3.55$ & .64 & & & \\
\hline Age (yr) & 73 & 0.97 & $0.94-1.00$ & .04 & 0.96 & $0.92-1.00$ & .05 \\
\hline PC-ASPECTS & 64 & 1.66 & $1.12-2.47$ & .01 & 1.77 & $1.14-2.73$ & .01 \\
\hline
\end{tabular}

${ }^{\mathrm{a}}$ OR from the final model multivariable model $(n=64)$.

Table 4: Univariable odds ratios, sensitivities, specificities, and area under ROC curves for the association between each predictor variable and binary $m R S$ (where $m R S>2$ is the reference group)

\begin{tabular}{llcccr}
\hline \multicolumn{1}{c}{ Predictor } & Positive Group & OR (95\% CI) & Sensitivity $(95 \% \mathrm{Cl})$ & Specificity $(95 \% \mathrm{Cl})$ & $\mathrm{AUC}(95 \% \mathrm{Cl})$ \\
\hline GCS & $\mathrm{GCS}>13$ & $5.70(1.97-16.47)$ & $0.60(0.39-0.79)$ & $0.79(0.65-0.90)$ & $0.70(0.58-0.81)$ \\
PC-ASPECTS & $>9$ & $4.03(1.36-11.98)$ & $0.57(0.35-0.77)$ & $0.76(0.60-0.88)$ & $0.66(0.54-0.78)$ \\
Age (yr) & $<68.5$ & $1.50(0.56-4.07)^{\mathrm{a}}$ & $0.64(0.43-0.82)$ & $0.46(0.31-0.61)$ & $0.55(0.43-0.69)$ \\
Multivariable model & $\operatorname{Pr}<0.32$ & $11.48(3.22-40.91)$ & $0.83(0.61-0.95)$ & $0.71(0.55-0.84)$ & $0.77(0.55-0.84)$ \\
\hline
\end{tabular}

Note:-AUC indicates area under the curve; Pr, predicted probability from the model; ROC, receiver operating characteristic.

a Not significant.

Table 5: Cross-tabulation and $\chi^{2}$ analyses for the association between $\mathrm{mRS}(0-2$ vs 3-6) and binary $\mathrm{mTICl}$ measures in the 73 patients with complete data

\begin{tabular}{|c|c|c|c|}
\hline & \multicolumn{2}{|c|}{ mRS } & \multirow[b]{2}{*}{$P^{1}$} \\
\hline & $0-2$ & $3-6$ & \\
\hline \multicolumn{4}{|c|}{$\mathrm{F}-\mathrm{mTICl}$} \\
\hline $0-2 a$ & 0 & 10 & \\
\hline $2 b-3$ & 25 & 38 & .01 \\
\hline \multicolumn{4}{|c|}{ I-mTICl } \\
\hline $0-2 a$ & 24 & 47 & \\
\hline $2 b-3$ & 1 & 1 & .63 \\
\hline
\end{tabular}

decrease in the odds of $m R S \leq 2$ is also expected and confirms the long-reported association of age with outcome in stroke. ${ }^{9,26,27}$ A F-mTICI $\geq 2 \mathrm{~b}$ was also significant for $\mathrm{mRS} \leq 2$, similar to other studies for the posterior circulation, confirming the importance of reperfusion, similar to that in the anterior circulation. $^{3,28}$ Our outcomes for $\mathrm{mTICI} \geq 2 \mathrm{~b}(86.30 \%)$ and $\mathrm{mRS} \leq 2(34.25 \%)$ are comparable with those in other articles specifically assessing endovascular treatment of basilar artery occlusion $^{9,10,28-30}$ and on the lower end of reported mortality rates of $25 \%-47 \% .^{10,29}$

Our study has a number of limitations. First, the nature of this single-service cohort means that there is self-adjudication. Second, patient numbers analyzed remained low; however, this finding reflects the lower proportion of PLVO as a part of stroke presentations overall. This number has affected some of our analyses, such as our ability to analyze the effect of the level of occlusion and the robustness of collaterals; however, we resisted the urge to further group these because doing so would create categories that share little clinical similarity. Third, there is heterogeneity in our prehospital process, in-hospital management, and endovascular therapy during the 7-year data collection, but this reflects the real-life evolution of treatment. It is possible that current outcomes may be better. Last, we did not seek to assess a broader range of clinical parameters such as serum glucose level, medical history, anticoagulation and other medications, and, of course, the NIHSS and hence could not include these in the analysis. However, this feature reflects the reality of endovascular stroke care: Much of the information above may not be immediately available at time of decision making.

\section{CONCLUSIONS}

Our study suggests that the presentation GCS, a rapidly calculated and well-understood clinical score for all clinician groups and seniorities, has correlation with patient outcome after posterior circulation MT. Absence of an identifiable infarction on presentation CT portends a better prognosis. We also confirm that functional independence is affected by recanalization and age.

Given the poor outcome of untreated PLVO, there is a tendency to treat patients regardless of presentation status and at longer timeframes. While this practice theoretically gives the patient the best possible chance of recovery, if through future research a point of futility can be established, then better use of health care resources can be established. The result of our study furthers this aim and, in the meantime, may give some guidance to clinical decision-making and informed consent.

Disclosures: Dana A. Hince-RELATED: Grant: Sir Charles Gairdner Hospital, Comments: The institute I work for has a tendered agreement with Sir Charles Gairdner Hospital to provide statistical support/data analysis to employees of that institution. My income is not dependent on this source, and I have received no money for the work I completed for this article.* *Money paid to the institution.

\section{REFERENCES}

1. Campbell BC, Mitchell PJ, Kleinig TJ, et al; EXTEND-IA Investigators. Endovascular therapy for ischemic stroke with perfusion-imaging selection. $N$ Engl J Med 2015;372:1009-18 CrossRef Medline 
2. Berkhemer OA, Fransen PS, Beumer D, et al; MR CLEAN Investigators. A randomized trial of intraarterial treatment for acute ischemic stroke. N Engl J Med 2015;372:11-20 CrossRef Medline

3. Goyal M, Demchuk AM, Menon BK, et al; ESCAPE Trial Investigators. Randomized assessment of rapid endovascular treatment of ischemic stroke. $N$ Engl J Med 2015;372:1019-30 CrossRef Medline

4. Saver JL, Goyal M, Bonafé A, et al; SWIFT PRIME Investigators. Stent-retriever thrombectomy after intravenous t-PA vs. t-PA alone in stroke. $N$ Engl J Med 2015;372:2285-95 CrossRef Medline

5. Jovin TG, Chamorro A, Cobo E, et al; REVASCAT Trial Investigators. Thrombectomy within 8 hours after symptom onset in ischemic stroke. $N$ Engl J Med 2015;372:2296-2306 CrossRef Medline

6. Bracard S, Ducrocq X, Mas JL, et al; THRACE investigators. Mechanical Thrombectomy After Intravenous Alteplase versus Alteplase Alone after Stroke (THRACE): a randomised controlled trial. Lancet Neurol 2016;15:1138-47 CrossRef Medline

7. Nagel S, Kellert L, Möhlenbruch M, et al. Improved clinical outcome after acute basilar artery occlusion since the introduction of endovascular thrombectomy devices. Cerebrovasc Dis 2013;36:394-400 CrossRef Medline

8. Schonewille WJ, Wijman CA, Michel P, et al; BASICS study group. Treatment and outcomes of acute basilar artery occlusion in the Basilar Artery International Cooperation Study (BASICS): a prospective registry study. Lancet Neurol 2009;8:724-30 CrossRef Medline

9. Singer OC, Berkefeld J, Nolte CH, et al; ENDOSTROKE Study Group. Mechanical recanalization in basilar artery occlusion: the ENDOSTROKE study. Ann Neurol 2015;77:415-24 CrossRef Medline

10. Luo G, Mo D, Tong X, et al. Factors associated with 90-day outcomes of patients with acute posterior circulation stroke treated by mechanical thrombectomy. World Neurosurg 2018;109:e318-28 CrossRef Medline

11. Inoa V, Aron AW, Staff I, et al. Lower NIH stroke scale scores are required to accurately predict a good prognosis in posterior circulation stroke. Cerebrovasc Dis 2014;37:251-55 CrossRef Medline

12. Heldner MR, Zubler C, Mattle HP, et al. National Institutes of Health stroke scale score and vessel occlusion in 2152 patients with acute ischemic stroke. Stroke 2013;44:1153-57 CrossRef Medline

13. Schneck MJ. Current stroke scales may be partly responsible for worse outcomes in posterior circulation stroke. Stroke 2018;49: 2565-66 CrossRef Medline

14. Olivato S, Nizzoli S, Cavazzuti M, et al. e-NIHSS: an expanded National Institutes of Health Stroke Scale weighted for anterior and posterior circulation strokes. J Stroke Cerebrovasc Dis 2016; 25:2953-57 CrossRef Medline

15. Pérez de la Ossa N, Carrera D, Gorchs $M$, et al. Design and validation of a prehospital stroke scale to predict large arterial occlusion: the rapid arterial occlusion evaluation scale. Stroke 2014;45:87-91 CrossRef Medline

16. Puetz V, Sylaja PN, Coutts SB, et al. Extent of hypoattenuation on CT angiography source images predicts functional outcome in patients with basilar artery occlusion. Stroke 2008;39:248590 CrossRef Medline

17. Liu X. Classification accuracy and cut point selection. Stat Med 2012;31:2676-86 CrossRef Medline

18. Turc G, Maïer B, Naggara O, et al. Clinical scales do not reliably identify acute ischemic stroke patients with large-artery occlusion. Stroke 2016;47:1466-72 CrossRef Medline

19. Alonso de Leciñana M, Kawiorski MM, Ximénez-Carrillo Á, et al; Madrid Stroke Network. Mechanical thrombectomy for basilar artery thrombosis: a comparison of outcomes with anterior circulation occlusions. J Neurointerv Surg 2017;9:1173-78 CrossRef Medline

20. Serles W, Gattringer T, Mutzenbach S, et al; Austrian Stroke Unit Registry Collaborators. Endovascular stroke therapy in Austria: a nationwide 1-year experience. Eur J Neurol 2016;23:906-11 CrossRef Medline

21. Alawieh A, Vargas J, Turner RD, et al. Equivalent favorable outcomes possible after thrombectomy for posterior circulation large vessel occlusion compared with the anterior circulation: the MUSC experience. J Neurointerv Surg 2018;10:735-40 CrossRef Medline

22. Mourand I, Machi P, Milhaud D, et al. Mechanical thrombectomy with the Solitaire device in acute basilar artery occlusion. $J$ Neurointerv Surg 2014;6:200-04 CrossRef Medline

23. Mansour OY, Megahed MM, Elghany E. Acute ischemic stroke prognostication, comparison between Glasgow Coma Score, NIHS Scale and Full Outline of UnResponsiveness Score in intensive care unit. Alexandria Journal of Medicine 2015;51:247-53 CrossRef

24. Tsao JW, Hemphill JC, Johnston SC, et al. Initial Glasgow Coma Scale score predicts outcome following thrombolysis for posterior circulation stroke. Arch Neurol 2005;62:1126-29 CrossRef Medline

25. Chandra RV, Law CP, Yan B, et al. Glasgow Coma Scale does not predict outcome post-intra-arterial treatment for basilar artery thrombosis. AJNR Am J Neuroradiol 2011;32:576-80 CrossRef Medline

26. Nakayama H, Jørgensen HS, Raaschou HO, et al. The influence of age on stroke outcome: the Copenhagen Stroke Study. Stroke 1994;25:808-13 CrossRef Medline

27. Greving JP, Schonewille WJ, Wijman CA, et al; BASICS Study Group. Predicting outcome after acute basilar artery occlusion based on admission characteristics. Neurology 2012;78:1058-63 CrossRef Medline

28. Mokin M, Sonig A, Sivakanthan S, et al. Clinical and procedural predictors of outcomes from the endovascular treatment of posterior circulation strokes. Stroke 2016;47:782-88 CrossRef Medline

29. Bouslama M, Haussen DC, Aghaebrahim A, et al. Predictors of good outcome after endovascular therapy for vertebrobasilar occlusion stroke. Stroke 2017;48:3252-57 CrossRef Medline

30. Gory B, Eldesouky I, Sivan-Hoffmann R, et al. Outcomes of stent retriever thrombectomy in basilar artery occlusion: an observational study and systematic review. J Neurol Neurosurg Psychiatry 2016; 87:520-25 CrossRef Medline 